\title{
Efficacy of Bleaching Treatment on Demineralized Enamel Treated with Resin Infiltration Technique
}

\author{
Luciana Floriani Thives de Freitas Santos, Heleine Maria Chagas Rêgo, Alessandra Bühler Borges \\ Cesar Rogério Pucci, Carlos Rocha Gomes Torres
}

\begin{abstract}
The aim of this study was to investigate the effect of bleaching treatment with $10 \%$ carbamide peroxide in white spot lesionsaffected teeth treated with caries infiltration technique. Cylindrical enamel-dentin specimens were prepared from bovine incisors. Baseline color measurement was performed by a spectrophotometer using the CIE L*a*b* system and specimens were divided in two groups: Sound (S) and demineralized (D) enamel. The group $S$ was divided into two subgroups ( $n=20)$ : Nonbleached (SNB) and bleached (SB). The group D was divided in four subgroups ( $n=20)$ : N onbleached (DNB), bleached (DB), resin infiltrated/nonbleached (DRNB) and resin infiltrated/ bleached (DRB). Artificial white spot lesions were produced in all groups $D$, simulating the presence of active lesions in labial tooth surface, and after demineralization, caries infiltration with low viscosity resin was performed in the resin infiltrated groups. In the bleached groups, $10 \%$ carbamide peroxide gel was applied ( 2 hours/day for 14 days). New color measurements were performed after bleaching and color alteration was calculated using $\Delta \mathrm{E}$ parameter. Data were submitted to oneway ANOVA and Tukey test (5\%). There were significant differences among groups when $\Delta E$ was evaluated $(p=0.001)$. Means ( \pm standard deviation) and results of Tukey test were: SNB $(2.53 \pm 0.48) a$; DRNB $(2.88 \pm 1.03)$ ab; DNB $(3.15 \pm 0.65)$ ab; DRB $(2.88 \pm 1.03) b c$; SB $(4.33 \pm 0.93)$ cd; DB $(5.27 \pm 1.33) d$. The bleaching treatment with $10 \%$ carbamide peroxide produced no significant color alteration in demineralized enamel treated with resin infiltration technique.
\end{abstract}

Keywords: Dental caries, Dental enamel, Tooth bleaching.

How to cite this article: Santos LFTF, Rêgo HMC, Borges $A B$, Pucci CR, Torres CR G. Efficacy of Bleaching Treatment on Demineralized Enamel Treated with Resin Infiltration Technique. World J Dent 2012;3(4):279-283.

\section{Source of support $\mathrm{Nil}$}

\section{Conflict of interest: None declared}

\section{INTRODUCTION}

The whitish appearance of initial enamel caries lesions is due to the presence of internal porosities beneath an apparently intact surface layer. ${ }^{1} \mathrm{~A}$ Ithough, some laboratorial studies have shown some degree of remineralization with the exposure of white spot lesions to different forms of fluoride application, ${ }^{2,3}$ clinical studies have demonstrated that long-existing white spot lesions are stable regarding de- and remineralization process and fluoride does not seem to have a significant effect on these lesions. ${ }^{4,5}$

This means that although an initial enamel caries can become arrested and change its clinical appearance from a chalky and rough active lesion to a bright and smooth inactive lesion, it sel dom disappear clinically. ${ }^{4,6}$ In addition, during the arresting process, stains can be incorporated into the lesion and the esthetic can be further compromised. ${ }^{7}$

Caries infiltration represents an alternative therapeutic technique to prevent the progression of these lesions, by means of penetration of a low viscosity resin into the enamel porosity, blocking the spread of cariogenic acids and the mineral dissolution. 8,9

A $n$ additional positive effect of the caries infiltration technique is that the penetration and polymerization of the low viscosity resin inside the lesion body allows a change of the lesion's whitish appearance to the natural enamel appearance. This approach may be indicated not only to arrest early carious lesions, but also to improve the esthetic appearance of the tooth, masking the white spot lesions. ${ }^{7,8}$

Color is an important factor affecting the esthetic of teeth and is influenced by a combination of intrinsic color and the presence of extrinsic stains that can be deposited on the tooth surface. ${ }^{10}$ The use of tooth whitening agents has grown considerably in recent years as the goal of reversing undesirable esthetic stains has increased. These bleaching products usually contain hydrogen peroxide or carbamide peroxide as the active agent. ${ }^{11}$

The mechanism by which these bleaching agents work is based on the action of hydrogen peroxide which is applied directly on the tooth surface. When carbamide peroxide is applied to the tooth surface a chemical reaction occur that result in the release of hydrogen peroxide. ${ }^{12}$ The hydrogen peroxide can diffuse inside enamel and dentin, decomposing into highly reactive free radicals, which result in tooth whitening via the oxidation of chromogenic molecules. ${ }^{12,13}$

When the white spot lesion is masked by the caries infiltration technique, the chalky white appearance is removed and the area is restored to the original enamel color. Nevertheless, this may give the impression of darkening of teeth by the patients, since they were used to the presence of the white spot lesions. This can motivate the desire for bleaching treatment. However, the penetration of infiltrant resin inside white spot lesions acts as a blocking agent ${ }^{7,9}$ and can alter the permeability of enamel to bleaching agents, possible interfering with the bleaching treatment.

Resin infiltration in labial white spot lesions may be desirable in order to improve esthetics; nevertheless, if 
general tooth color alteration is desirable, the bleaching treatment should be performed before resin infiltration, because the presence of a light cured resin inside tooth structure may hamper the action of whitening agents.

The aim of this study was to investigate the effect of bleaching treatment with $10 \%$ carbamide peroxide on active white spot lesions-affected teeth treated with caries infiltration technique. The null hypothesis tested was that the application technique of the infiltrant resin for the treatment of white spot lesions does not interfere in the bleaching agent action.

\section{MATERIALS AND METHODS}

\section{Sample Preparation}

The methods described by Wiegand et al ${ }^{14}$ were used to prepare the specimens. For that, 60 extracted, nondamaged bovine intact incisors were stored in $0.1 \%$ thymol solution at room temperature until used. From each crown two enamel-dentin specimens, $3 \mathrm{~mm}$ in diameter and $2.2 \mathrm{~mm}$ in height w ere prepared from the labial surface with a Trephine Mill.

The specimens were attached to a metal holder and $0.1 \mathrm{~mm}$ of enamel was removed by polishing with sequential aluminum oxide abrasive papers $(1,200,2,400$ and 4,000 grit - FEPA-P; Struers, Ballerup, Denmark) in a polishing device (DP-10, Panambra Industrial e Técnica SA, São Paulo, SP, B razil) for 20 seconds each. The dentin side of specimens was abraded with a 1,200 grit abrasive paper, removing $0.1 \mathrm{~mm}$ of dentin and resulting in specimens of 1 $\mathrm{mm}$ of enamel $(E)$ and $1 \mathrm{~mm}$ of dentin (D). The prepared ED specimens were examined under the stereomicroscope to certify the absence of cracks or other surface defects. A fter preparation, the specimens were stored in deionized water to avoid dehydration.

Baseline color reading was assessed on the enamel surface of the specimens at standardized ambient conditions using a Spectrophotometer CM-2600d (K onica M inolta, Osaka, Japan), which was set to 'Small area view' (SA V). The color and spectral distribution were measured according to the CIE L* $a^{*}$ b* system, using Spectramagic software (K onica M inolta). The standard illuminant D 65 was set, with the reflectance mode and the ultraviolet light included. The observer angle was set to $2^{\circ}$ and the specular component was included $(\mathrm{SCl})$.

The samples were carefully dried with an absorbent paper (not desiccated) and immediately placed into individually prepared metal holders with a $3 \mathrm{~mm}$ diameter reading window and the baseline color reading of specimens were performed.
The results of color measurement were quantified in terms of the coordinate value $L^{*}, a^{*}$ and $b^{*}$ established by the Commission International de l'Eclariage (CIE), which locates the color of an object in a three-dimensional color space. The $L *$ axis represents the degree of lightness within a sample and ranges from 0 (black) to 100 (white). The a* plane represents the degree of green/red color, while the $b^{*}$ plane represents the degree of blue/yellow within the sample. The spectrophotometer was set to make three consecutive readings, automatically calculating the mean values of $L^{*}$ $a^{*} b^{*}$. M ean $L^{*}$ value of each ED specimens was used for stratified allocation among groups of all samples among the various experimental groups, in order to balance the initial data.

The groups were divided into two groups: $\mathrm{S}$-sound enamel $(n=40)$ and D-demineralized enamel $(n=80)$. The group $S$ was divided into two subgroups $(n=20)$ : nonbleached (SNB) and bleached (SB). The group D was divided in four subgroups $(n=20)$ : nonbleached $(D N B)$, bleached (DB), resin infiltrated/nonbleached (DRNB) and resin infiltrated/bleached (DRB).

\section{Demineralization Process}

A rtificial enamel subsurface lesions were created in order to simulate the presence of active white spot lesions in the labial surface of tooth by individually immersing and storing the specimens in a buffer solution, according to Queiroz et $\mathrm{al}^{3}$ proposal. The demineralizing solution was composed of $50 \mathrm{mM}$ acetate buffer solution containing $1.28 \mathrm{mM}$ $\mathrm{Ca}\left(\mathrm{NO}_{3}\right)_{2} \cdot 4 \mathrm{H}_{2} \mathrm{O}, 0.74 \mathrm{mM} \mathrm{NaH}{ }_{2} \mathrm{PO}_{4} \cdot 2 \mathrm{H}_{2} \mathrm{O}$, and $0.03 \mathrm{ppm}$ $\mathrm{F}$ at pH 5.2 for 24 hours. The specimens were immersed separately in an unstirred solution at $37^{\circ} \mathrm{C}$. The total volume of solution used was calculated using $2 \mathrm{ml} / \mathrm{mm}^{2}$ of the enamel area.

A rtificial sal iva was prepared according to theformulation of Gohring et al ${ }^{15}$ and consisted of hydrogen carbonate (22.1 $\mathrm{mmol} / \mathrm{l})$, potassium (16.1 mmol/l), sodium $(14.5 \mathrm{mmol} / \mathrm{l})$, hydrogen phosphate $(2.6 \mathrm{mmol} / \mathrm{l})$, boric acid $(0.8 \mathrm{mmol} / \mathrm{l})$, calcium $(0.7 \mathrm{mmol} / \mathrm{l})$, thiocyanate $(0.2 \mathrm{mmol} / \mathrm{l})$ and magnesium $(0.2 \mathrm{mmol} / \mathrm{l})$. The $\mathrm{pH}$ was adjusted to 7.0 .

A fter demineralization, the color of specimens was measured again, the same way as described previously and the $L^{*}$ value of each specimen was used for stratified allocation of all samples among the four demineralized groups.

\section{Resin Infiltration}

The specimens of groups DRNB and DRB were submitted to resin infiltration technique using the infiltration resin 
Efficacy of Bleaching Treatment on Demineralized Enamel Treated with Resin Infiltration Technique

(Icon ${ }^{\circledR}$, DM G, Hamburg, Germany). The infiltration procedure was performed according to the manufacturer's instructions. A $15 \%$ hydrochloric acid gel (Icon-Etch) was applied on the demineralized enamel surface for 2 minutes and then water rinsed and air dried for 30 seconds, follow ed by the application of ethanol (I con-D ry) during 30 seconds and additional air drying. The low-viscosity resin infiltrant (Icon-Infiltrant) was applied on the surface two times, the first time for 3 minutes and the second time for 1 minute. Both applications were light cured for 40 seconds. Specimens were polished with aluminum oxide abrasive papers (4000 grit - FEPA-P; Struers, B allerup, Denmark), for about 20 seconds to removal of the excess resin, using a micrometer to verify the specimens height before and after the resin application.

\section{Bleaching}

Specimens of groups SB, DB and DRB were submitted to bleaching treatment with $10 \%$ carbamide peroxide (W hiteness Perfect, FGM , J oinville, SC, B razil), for 2 hours during 14 days. In the intermediate periods, specimens were stored in artificial saliva. After the end of treatment, they were stored in artificial saliva which was changed daily for 7 days and a new color measurement was performed. The groups SNB, DNB and DRNB remained in daily changed artificial saliva during this period (21 days).

$\mathrm{New}$ color measurements were performed after this period. For each measurement, the values of $L^{*}, a^{*}$ and $b^{*}$ were recorded and the values of the changes of $L^{*}(\Delta L)$, of $a^{*}(\Delta a)$, and $b^{*}(\Delta b)$ were calculated. A fter, the total change color or the variation in color perception of each tooth was calculated, designated by the abbreviation $\Delta \mathrm{E}$. This parameter was calculated according to the following formula:

$$
\Delta \mathrm{E}=\left[(\Delta \mathrm{L})^{2}(\Delta \mathrm{a})^{2}(\Delta \mathrm{b})^{2}\right]^{1 / 2}
$$

The data were statistically analyzed using the software Statistica for W indows 9.0 (Statsoft, Tulsa, OK, USA) using one-way ANOVA and Tukey test at a significant level of 0.05 .

\section{RESULTS}

The application of one-way A NOV A revealed significant differences among groups when $\triangle \mathrm{E}$ parameter was evaluated $\left(p=0.0001 / F=18.245\right.$ for $5^{\circ}$ of freedom $)$. The Tukey test was then applied and showed that group SN B exhibited the lowest color alteration, significantly lower than the SB group. Specimens of group DB presented the higher color alteration values, significantly higher than DNB group.
Nevertheless, the comparison between groups DRB and DRNB showed no significant differences in $\triangle E$ values (Table 1).

\section{DISCUSSION}

Although the main objective of resin infiltration of white spot lesion is the prevention of caries progression, a positive effect of the use of this technique is the instantaneous esthetic improvement obtained when used in labial white spot Iesions. This technique is less invasive than microabrasion with hydrochloridric acid and pumice, which is commonly used as an attempt to improve esthetic of white spot lesions and also can be combined with conventional esthetic restorations in more severe cases. ${ }^{7,8}$ The effectiveness of the caries infiltration technique in masking white spot lesion, altering the whitish aspect of demineralized enamel and returning the tooth to its natural color was observed in previous studies. ${ }^{7,8,16}$

This masking effect is a consequence of the filling of subsurface porosities present in the lesion body with the low viscosity resin. This occurs due to the refractive index of the infiltrant resin (1.475), which is more similar to the refractive index of enamel (1.65) than water (1.33) and air (1.0) that usually fill these micropososities. When filled with resin, the lesion recovers the translucency, appearing similar to the surrounding enamel, improving the esthetic appearance of tooth. 7,16

In fact, the esthetic outcome cannot be accurately predicted, but even if the whole whitish lesion is not completely masked, there is a considerable improvement of tooth appearance after resin infiltration. ${ }^{7}$ The outcome might be dependent on the lesion depth and activity, that is, better results might be achieved with more active and younger state when the surface layer is thinner and the lesion is not so deep. ${ }^{17}$ However, when these white spot lesions are masked, some patients may, by the other side, have an impression of 'darkening' of teeth, since the whitish appearance disappears and the real color of the teeth returns. This may encourage the desire for bleaching after a caries infiltration technique, and in these cases, the presence of a resin inside tooth structure could affect the action of the whitening gel.

Although in the present study the artificial caries was created on enamel only, in order to simulate active white spot lesions in the labial surface, the specimens were composed by enamel and dentin, in order to simulate the optical properties of the tooth, as the apparent color is a result of the diffuse reflectance from dentin through the enamel layer. ${ }^{18}$

The null hypothesis proposed was rejected, since the group infiltrated with resin (group DRB) presented no 
significant color alteration compared to group DRNB, showing that the presence of low viscosity resin interfered with tooth whitening process using $10 \%$ peroxide carbamide gel.

Both enamel and dentin are permeable to hydrogen peroxide and carbamide peroxide, allowing the decomposition of bleaching agents in highly reactive free radicals that oxidize organic stains within the tooth. The penetration of these bleaching agents into tooth structure occurs due to their low molecular weight and ability to denaturate proteins, increasing the ion movement through the tooth tissues. ${ }^{14,19,20}$ Although the barrier created by the infiltration of the resin into the microporosities of the lesion is intended to block the diffusion pathways for cariogenic acids, depending on the pore volume of the lesion, it may not be completely embedded with the resin and also, resin shrinkage may occur during light curing. ${ }^{21-23}$ In these situations, it might be expected that some peroxide could penetrate through lesion and act in the subsurface tooth structures. N everthel ess, significant color alteration was not observed in resin-infiltrated bleaching specimens of this study, indicating that the presence of resin prevented the penetration of bleaching agent into the tooth tissues.

The bleaching treatment with 10\% CP was effective in produce significant color alteration both in sound and demineralized enamel groups, as observed in Table 1. A thome bleaching treatment was previously reported to cause no exacerbation of enamel demineralization. ${ }^{24}$ Thus, after preventive measures, such as diet orientation and oral hygiene instructions, the esthetic planning of resininfiltration for white spot lesions color masking should include bleaching treatment before resin-infiltration, if tooth general color alteration is desired by the patient.

Nevertheless, although no significant color alteration was obtained when bleached and nonbleached resin infiltrated groups were compared, it must be taken into consideration that all specimen surface were demineralized and infiltrated. But in clinical situations, this usually occurs in some parts of tooth crown, especially around orthodontic brackets. In such cases, the sound enamel around the demineralized tissue can allow the penetration of the

Table 1: $\Delta \mathrm{E}$ values (mean and standard deviation) of all experimental groups and results of Tukey test

\begin{tabular}{lllllll}
\hline Groups & Mean & SD & \multicolumn{4}{l}{ Homogeneous groups* } \\
\hline SNB & 2.537 & 0.481 & A & & & \\
DRNB & 2.880 & 1.030 & A & B & & \\
DNB & 3.156 & 0.651 & A & B & & \\
DRB & 3.591 & 1.328 & & B & C & \\
SB & 4.337 & 0.936 & & & C & D \\
DB & 5.273 & 1.332 & & & & D \\
\hline
\end{tabular}

$* p<0.05$ bleaching agents inside tooth structure, possibly enabling the bleaching action in the internal parts of enamel and dentin. Thus, further studies are required to investigate the interaction between resin infiltrated lesions and bleaching agents as well as their interaction with the remaining sound tissues of tooth.

\section{CONCLUSION}

Within the limitations of this study, it can be concluded that the bleaching treatment with $10 \% \mathrm{CP}$ produced no significant color alteration in resin infiltrated tested specimens.

\section{REFERENCES}

1. Paris S, B itter K, Renz H, H opfenmuller W, M eyer-L ueckel H. $V$ alidation of two dual fluorescence techniques for confocal microscopic visualization of resin penetration into enamel caries lesions. M icrosc Res Tech 2009 J ul;72(7):489-94.

2. $Y$ amazaki $H$, Litman $A, M$ argolis HC. Effect of fluoride on artificial caries lesion progression and repair in human enamel: Regulation of mineral deposition and dissolution under in vivolike conditions. A rch O ral Biol 2007 Feb;52(2):110-20.

3. Queiroz CS, HaraA T, V aleA M P, Cury JA.PH-cycling models to evaluate the effect of low fluoride dentifrice on enamel deand remineralization. B raz Dent J 2009;19:21-27.

4. Zantner C, M artus P, K iel bassa AM . Clinical monitoring of the effect of fluorides on long-existing white spot lesions. A cta Odontol Scand 2006 A pr;64(2):115-22.

5. W illmot DR. White lesions after orthodontic treatment: Does low fluoride make a difference? J Orthod 2004Sep;31(3): 235-42.

6. Cury JA, Tenuta L M . Enamel remineralization: Controlling the caries disease or treating early caries lesions? Braz Oral Res 2009;23(Suppl 1):23-30.

7. Paris S, M eyer-L ueckel H. M asking of labial enamel white spot lesions by resin infiltration: A clinical report. Quintessence Int 2009 Oct; 40(9):713-18.

8. K ielbassa A M , M uller J, Gernhardt CR. Closing the gap between oral hygiene and minimally invasive dentistry: A review on the resin infiltration technique of incipient (proximal) enamel lesions. Quintessence Int 2009 Sep;40(8):663-81.

9. M eyer-L ueckel H, Paris S. Improved resin infiltration of natural caries lesions. J Dent Res 2008 Dec;87(12):1112-16.

10. J oiner $A$. The bleaching of teeth: A review of the literature. J Dent 2006 A ug;34(7):412-19.

11. J oiner A, Hopkinson I, Deng $Y$, W estland S. A review of tooth colour and whiteness. J Dent 2008;36(Suppl 1):S2-7.

12. Dahl JE, Pallesen U. Tooth bleaching: A critical review of the biological aspects. Crit Rev Oral B iol M ed 2003;14(4):292-304.

13. Schiavoni RJ, Turssi CP, Rodrigues A L Jr, Serra M C, Pecora JD, Froner IC. Effect of bleaching agents on enamel permeability. A m J Dent 2006 Oct;19(5):313-16.

14. W iegand $A$, V ollmer D, Foitzik M, Attin R, A ttin T. Efficacy of different whitening modalities on bovine enamel and dentin. Clin Oral Investig 2005 J un;9(2):91-97.

15. Gohring TN, Zehnder M, Sener B, Schmidlin PR. In vitro microleakage of adhesive-sealed dentin with lactic acid and 
saliva exposure: A radio-isotope analysis. J Dent 2004 $M$ ar;32(3):235-40.

16. Torres CRG, Borges AB, Torres LM, Gomes IS, de Oliveira RS. Effect of caries infiltration technique and fluoride therapy on the colour masking of white spot lesions. J Dent 2010 $M$ ar;39(3):202-07.

17. Kim S, K im EY, J eong TS, K im JW. The evaluation of resin infiltration for masking labial enamel white spot lesions. Int J Paediatr Dent 2011 J ul;21(4):241-48.

18. O'B rien WJ. D ouble layer effect and other optical phenomena related to esthetics. Dent Clin North A m 1985 Oct;29(4): 667-72.

19. Camargo SE, V alera M C, C amargo CH, Gasparoto M ancini M N, M enezes M M . Penetration of $38 \%$ hydrogen peroxide into the pulp chamber in bovine and human teeth submitted to office bleach technique. J Endod 2007 Sep;33(9):1074-77.

20. Thitinanthapan $W$, Satamanont $P$, V ongsavan $N$. In vitro penetration of the pulp chamber by three brands of carbamide peroxide. J Esthet Dent 1999;11(5):259-64.

21. M eyer-L ueckel $H$, Paris S. Progression of artificial enamel caries lesions after infiltration with experimental light curing resins. Caries Res 2008;42(2):117-24.

22. Paris S, M eyer-Lueckel H, Colfen H, K ielbassa AM. Resin infiltration of artificial enamel caries lesions with experimental light curing resins. Dent M ater J 2007J ul;26(4):582-88.

23. Paris $S, M$ eyer-L ueckel $H, K$ ielbassa $A M$. R esin infiltration of natural caries lesions. J Dent Res 2007 J ul;86(7):662-66.

24. Pinto CF, Paes L eme A F, Cavalli V, Giannini M . Effect of $10 \%$ carbamide peroxide bleaching on sound and artificial enamel carious lesions. Braz Dent J 2009;20(1):48-53.

\section{ABOUT THE AUTHORS Luciana Floriani Thives de Freitas Santos}

PhD Student, Department of Restorative Dentistry, São José dos Campos School of Dentistry - UNESP - São Paulo State University São J osé dos Campos, São Paulo, B razil

\section{Heleine Maria Chagas Rêgo}

PhD Student, Department of Restorative Dentistry, São José dos Campos School of D entistry - UNESP - São Paulo State University São J osé dos Campos, São Paulo, B razil

\section{Alessandra Bühler Borges}

A ssistant Professor, Department of Restorative Dentistry, São J osé dos Campos School of Dentistry-UNESP-São Paulo State University, São J osé dos Campos, São Paulo, B razil

CorrespondenceAddress: A V Eng. Francisco J osé L ongo, 777, Jd São Dimas, São José dos Campos, São Paulo 12245-000, Brazil Phone: +55-12-39479048, e-mail: alessandra @ fosjc.unesp.br

\section{Cesar Rogério Pucci}

Assistant Professor, Department of Restorative Dentistry, São J osé dos Campos School of Dentistry-UNESP-São Paulo State University, São J osé dos Campos, São Paulo, B razil

\section{Carlos Rocha Gomes Torres}

Assistant Professor, Department of Restorative Dentistry, São J osé dos Campos School of Dentistry-UNESP-São Paulo State University, São J osé dos Campos, São Paulo, B razil 